\title{
Faculty perceptions of webcasting in health sciences education
}

\author{
Barbara A. Gushrowski ${ }^{1}$ and Laura M. Romito ${ }^{2}$
}

Abstract: Pre-recorded lectures (podcasts) and recordings of live lectures (lecture-capture) are now everyday occurrences on many college campuses. Student use and opinions of these technologies have been frequently studied. However, there has been little reported on how faculty perceive these technologies. This article reports the results from a 2010 survey of dental, medical, and nursing faculty about their experiences with podcast/lecture capture technologies as teaching tools. A 46-item survey was distributed electronically to full-time faculty at the schools of Dentistry, Medicine, and Nursing on the campus of an urban university in Fall 2010 to determine their experiences and perceptions of podcast/lecture capture technologies as teaching tools. Of the 398 respondents, $32 \%$ employed lecture capture while only $2 \%$ used podcasting. Of those faculty not currently recording materials, 83 (68\%) stated that they plan to do so in the next 2 years. Lack of time, 26 (24\%) and training, (22\%) are major reasons stated for not recording course content. Although a large number of faculty believe student learning has improved through the use of these technologies $(74 \%, n=86)$, few stated that test scores have improved following implementation of electronic delivery of course materials $(29 \%, n=34)$. There was no correlation between the use of podcast/lecture capture technologies and faculty gender, school, or years of teaching. A wide array of technologies to record lectures and present additional course materials electronically are in use at the health sciences programs on the campus. Overall, faculty view these technologies in a favorable light.

Keywords: podcasting, lecture capture, health sciences, faculty perceptions

\section{Introduction}

Currently the term "podcast" describes both audio and/or video files that can be downloaded and played on a personal computer or mobile device. For example, lectures, based on a Microsoft Power Point slideshow along with a recording of the instructor's lecture narration can be downloaded and played on a laptop computer. Such video podcasts can be pre-recorded and distributed in advance or in lieu of class, or they can be generated during the class session as "lecture capture" and made available subsequent to the class session. For the purposes of this paper a podcast is defined as any presentation that is pre-recorded and lecture capture refers to a presentation that is recorded live.

Pre-recorded lectures, supplemental, and study materials, as well as recordings of live lectures and streaming live video feeds of a lecture are now everyday occurrences on many college campuses (Owston, Lupshenyuk, \& Wideman, 2011). The use of podcasting, lecture capture, and other electronic delivery mechanisms has, in a relatively short period of time, become an accepted practice of instructional delivery in health science programs (Nast, Schafer-

\footnotetext{
${ }^{1}$ Associate Librarian, Indiana University School of Dentistry, bgushrow@iu.edu

${ }^{2}$ Associate Professor, Department of Oral Biology, Indiana University School of Dentistry, 1romitoc@iu.edu
} 
Hesterberg, Zielke, Sterry, \& Rzany, 2009; Walmsley, Lambe, Perryer, \& Hill, 2009; Zanussi, Paget, Tworek, \& McLaughlin, 2011). These materials are made available to students via iTunes, school websites, or proprietary courseware products. Despite the expanded use of these new technologies and their popularity with many students, there is a dearth of information regarding faculty use and perceptions of these instructional delivery methods. Thus, the purpose of this study was to gather data about how faculty across various health science professions at one large urban Midwestern university campus perceive these new technologies. Specifically, we posed the following research questions:

1. To what extent are health sciences faculty using these technologies?

2. Is there a difference in use and perceptions of webcasting technologies among faculty based on health science program, gender, or years of teaching experience?

3. What do faculty perceive to be advantages / disadvantages for themselves and for their students in using these technologies?

4. What, if anything, do faculty perceive as barriers to using these technologies?

\section{Literature Review}

The increasing use of these technologies in education is reflected in the growing number of articles devoted to the topic. Rainsbury (Rainsbury \& McDonnell, 2006) reported that a search in the PubMed database in 2006 found only 3 articles about podcasting in health sciences education. In 2010, "Webcasts as Topic" was added as a MeSH term by the National Library of Medicine and 'webcast' is now listed in PubMed as a publication type. A 2011 PubMed search on podcasting in health sciences education yielded over 100 articles.

Many of the articles published over the past 5 years fall into 3 broad categories: basic how-to, student satisfaction, and student learning. Articles in the how-to category, many of which were published from 2006-2008, define key terms, describe the technologies, and outline methods of producing podcasts and distributing recordings (Cain \& Fox, 2009; Corl, Johnson, Rowell, \& Fishman, 2008; Elkind, 2009; Hopp, 2010; Jham, Duraes, Strassler, \& Sensi, 2008; Kennedy, Gray, \& Tse, 2008; Long \& Edwards, 2010; McCartney, 2006; Rowell, Corl, Johnson, \& Fishman, 2006; Ruiz, Mintzer, \& Leipzig, 2006).

Authors have used a variety of theoretical frameworks to explain student satisfaction with the technology and the method of content delivery. Kardong-Edgren \& Emerson use constructivist theory to explain that students who download and listen to a podcast may expect this activity to improve their grade, thereby making the lecture recording more meaningful. They further use five constructs to "explain a user's motivation for seeking, using, and continuing to use an electronic media technology: cognitive needs, affective needs, personal integrative needs, social integrative needs, and entertainment needs."(Kardong-Edgren \& Emerson, 2010). Stiffler et al, state that educational podcasting is consistent with "...Siemens' Digital Age Orientation to Learning and other connectivism theorists." Connectivism theorists assert that knowledge exists outside the individual and in order for students to learn, this knowledge must connect "...to the right people at the right time and in the right context." (Stiffler, Stoten, \& Cullen, 2010). Vogt et al., also discuss Siemans' connectivism theory along with Mayers' Multimedia Learning Theory - that students will learn through several avenues including visual and auditory - to frame their study of undergraduate nursing students' learning and satisfaction with podcasting (Vogt, Schaffner, Ribar, \& Chavez, 2010). Others have reported survey results that focused on student satisfaction with the technology and the method of content delivery, though without a theoretical

Journal of Teaching and Learning with Technology, Vol. 3, No. 1, June 2014. 
framework (Bollmeier, Wenger, \& Forinash, 2010; Forbes \& Hickey, 2008; Lymn \& Bowskill, 2010; McKinney \& Page, 2009; Nast et al., 2009; Patasi, Boozary, Hincke, \& Jalali, 2009; Pilarski, Alan Johnstone, Pettepher, \& Osheroff, 2008; Reynolds, Mason, \& Eaton, 2008; Schlairet, 2010; Shantikumar, 2009; Walmsley et al., 2009).

In addition, papers have reported students' perception of the value of podcasts as learning and exam preparation tools. More recently, efforts have been undertaken to assess these technologies in light of student learning outcomes. Bollmeier et al., posit that cognitive load theory may explain why recorded lectures may improve learning. Cognitive load theory describes learning taking place at three levels - short-term, working, and long-term memory. Information is first processed through short-term memory into working memory. When too much information or poorly organized information is processed, the constraints on working memory don't allow the information to be fully processed into long-term memory. Recorded lectures allow the students to review and process the information in smaller chunks and allows time for students to reflect on the information and thus transfer it into long-term memory (Bollmeier et al., 2010). Studies by Bhatti et al, Greenfield, O'Neill et al, and Schreiber et al, demonstrated that compared to standard instructional methods such as lecture, learning outcomes for students viewing podcasts are improved (Bhatti et al., 2009; Greenfield, 2011; O'Neill, Power, Stevens, \& Humphreys, 2010; Schreiber, Fukuta, \& Gordon, 2010). However, Hadley et al., Nagler et al., and Vogt et al., reported no significant differences in exam scores between students receiving in-person and online content delivery. (Hadley et al., 2010; Nagler, Andolsek, Dossary, Schlueter, \& Schulman, 2010; Vogt et al., 2010)

While the student viewpoint and opinions of these technologies have been frequently studied, to date there has been little reported on how faculty perceive these technologies. One faculty concern is decreased student attendance in class. Some investigators did not find this to be a significant issue (Copley, 2007; Forbes \& Hickey, 2008; Lymn \& Bowskill, 2010; Meade, Bowskill, \& Lymn, 2009; Nast et al., 2009; Pilarski et al., 2008), however, Kardong-Edgren (Kardong-Edgren \& Emerson, 2010) found that faculty reported increasing student absenteeism after increased availability of podcasts. Bhatti (Bhatti et al., 2009) discussed demands on faculty's time in learning and implementing these technologies. Another concern that has been noted is the ease with which online materials can be broadly disseminated which may result in the inadvertent or intentional violation of faculty intellectual property rights by students (Johnson \& Grayden, 2006; Read, 2007).

One recent paper does report on some aspects of faculty views on webcasting in the classroom. A survey of 66 North American dental schools was conducted about the use of lecture recordings in dental education (Horvath et al., 2013). Several questions on the survey related specifically to faculty preparation for using the technologies and barriers experienced by faculty in implementation. Nearly half of those responding to questions about faculty preparation (13) reported that formal training was available for faculty on the use of the recording technology, while $26 \%$ (7) reported no preparation or training prior to implementation. The barriers most reported were faculty resistance, technology problems, concerns about intellectual property, and fears that attendance in face-to-face lectures would decline. According to adoption-diffusion theories, faculty acceptance of a new instructional technology such as webcasting is a complicated, multidimensional process involving cognitive, emotional and contextual factors. The adoption process involves the individual faculty member's decision to utilize the technology, while diffusion refers to adoption by a collective, such as at the school or campus level. A faculty member's perception of the new technology is influenced by numerous factors 
including their perception of whether the innovation is useful and if they would be capable of successfully employing it, as well as their observation of others' success (or failure) with use of the technology (Straub, 2009).

Our study was grounded in adoption - diffusion theories such as the Technology Acceptance Model (TAM) and the Universal Technology Adoption and Use Theory (UTAUT), which purport that a faculty member's adoption of new technology is based on his/her perceptions of the ease of use and utility of that technology. Additionally, the UTAUT also considers whether the faculty feels social / environmental pressure to use the technology and the extent to which they perceive institutional support for its use. Other factors moderating the decision to adopt a new technology such as podcasting that are also addressed by this theory are the age, gender and experience of the faculty (Straub, 2009). As such, these constructs were incorporated into our survey.

In an effort to elucidate faculty perceptions of podcast/lecture capture technologies as teaching tools in health sciences education, we conducted a campus-wide survey of dental, medical, and nursing faculty about their experiences with these technologies. This article reports on the results of the survey in which faculty were asked about the following: the extent to which they use these technologies, the system/software used, perceived advantages and disadvantages for themselves and their students, and the effects on student learning outcomes.

\section{Methods}

\section{Study Population}

The study participants were comprised of full-time faculty from the Schools of Dentistry, Medicine, and Nursing on the campus of an urban Midwestern university. This campus is predominantly a health sciences campus. Courses in health sciences programs such as medicine, dentistry, and nursing tend to have traditional content-dense lectures which would be amenable to these webcasting technologies.

Upon our request, a list of names and campus email addresses of all full-time health sciences faculty were compiled by each of the respective schools and sent us. A total of 1454 names and email addresses were submitted and all were contacted by email and asked to participate in the voluntary, confidential survey.

\section{Survey Instrument}

In 2009, we conducted a pilot survey at the School of Dentistry and many of the items from that survey were included in the current study. The 2009 survey consisted of 37 items including multiple-choice and yes/no questions as well as open-ended questions that focused on the following: advantages and disadvantages for students and faculty in employing podcasts and lecture capture, barriers to implementation, future interest in using these technologies, and student learning outcomes. In the current study, additional yes/no questions were added such as "Does your school use any type of lecture capture or podcasting system?" Additional multiple choice questions asked about the specific technology systems available at the schools and how these systems are managed. Demographic questions about the number of years of teaching experience and number of years teaching at this campus were also included. With these additions, the current survey contained a total of 46 items. 
The survey software, Qualtrics ${ }^{\mathrm{TM}}$ (Provo, UT), enabled a branching mechanism wherein all questions were not delivered to all participants, but were delivered based on responses to key survey items. For example, based on the response to the question - "How have you used the lecture capture or podcasting system?" - the participant was directed to additional questions related to the ease or difficulty of developing podcasts, lecture captures, or plans for future use of the technologies.

The survey included several open-ended items that allowed participants to comment freely on the advantages and disadvantages to faculty and students of using podcast and lecture capture technologies. Faculty who reported not already using the technology were asked to identify their perceived barriers to adoption and what would facilitate their use of webcasting technologies.

\section{Survey administration}

Following review and approval of the survey instrument and study protocol by the University Institutional Review Board, we distributed the 46- item survey in the Fall semester of 2010 via email. The initial email message described the purpose of the survey and invited participation by the 1454 full-time health sciences faculty. The email invitation indicated that the study was voluntary, participation implied consent, all responses were confidential, and results data would be reported in aggregate and not linked to any individual respondent. The message also included a link to the survey. While we did collect limited demographic data, we did not gather any personally identifiable information in the survey and faculty were not offered any incentives to participate. The survey was open for 3 weeks, and responses were password protected and stored on the Qualtrics ${ }^{\mathrm{TM}}$ server. The Qualtrics ${ }^{\mathrm{TM}}$ software is equipped to track non-responders so we composed follow-up messages encouraging completion of the survey which the software delivered to the non-responders in weeks 2 and 3.

After we collected the data, it was cleaned, coded and analyzed. Descriptive statistics were obtained and qualitative and quantitative analyses were performed. Quantitative analysis included frequencies and percentages, Somers'D Phi, and Cramer's V tests of correlation. Qualitative analysis of data from the open-ended survey items generated several response categories based on common themes. We analyzed the data using SPSS statistical software (v. 19.0 SPSS, Inc. Chicago, ILL 2011).

\section{Results}

A total of 398 health sciences faculty completed the survey for an aggregate response rate of $27 \%$. Response rate varied by health science school as follows: Dentistry $64 \%(\mathrm{n}=69)$; Nursing 57\% $(n=55)$, and Medicine 27.5\% $(n=274)$. Males accounted for $60 \%$ of the participants and females represented $40 \%(n=338)$. Reported years of teaching experience ranged from less than 1 year to over thirty years, with approximately $50 \%$ of respondents having at taught at least 15 years $(n=341)$. Reported years of teaching at this campus had an identical range, but with $70 \%$ reporting 15 years or less with this campus $(n=334)$.

Of the total number of respondents, $128(32 \%)$ used lecture capture software to record their live lectures, $9(2 \%)$ pre-recorded podcasts, 27 (7\%) used both methods of recording, and $121(30 \%)$ did not use either recording method. The remaining 113 faculty (28\%) did not answer 
this question. Eighty-one respondents $(20 \%)$ were not aware that their respective schools had podcast/lecture capture systems available.

Of those faculty reporting non-use of the technologies, $83(68 \%)$ indicated they would consider recording a podcast or lecture in the next 2 years, $33(27 \%)$ would not consider doing so, and $5(4 \%)$ did not answer this question. Those considering making recordings indicated that lack of time, $26(24 \%)$ and training, $24(22 \%)$ were the 2 biggest factors that were preventing them from adopting these technologies.

The recording software used varies widely between health science schools. Fifteen separate software packages were identified (see Appendix A.) and many respondents indicated they used more than 1 of these. Recording systems used for lecture capture are available on fixed workstations, 76 (49\%), portable devices, $45(29 \%)$, or both, $34(22 \%)$, and are managed to a large degree by school or university information technology departments. Lecture capture software is available in large lecture halls seating over 125 as well as small classrooms that seat fewer than thirty. A relatively large number of faculty, $98(32 \%)$ did not know the name of the system used by their school.

There is little standardization or consistency in the starting and stopping protocols for lecture capture. These procedures are carried out by school support staff, 97 (36\%), faculty, 90 $(33 \%)$, campus information technology staff, $50(18 \%)$, students, $33(12 \%)$, or automated by the system, $30(11 \%)$. In addition, 44 faculty (16\%) indicated that the initiation and rendering of lecture capture was conducted by some means other than the aforementioned methods; furthermore, of these 44 respondents, 31 did not know how the recordings were started and stopped.

Podcasting software for pre-recording lectures were used by 36 respondents (13\%), 9 of whom used this method exclusively, while 27 used podcasts in addition to lecture capture. The podcast software used was often the same as that used for lecture capture. There was only 1 exclusively podcast system named. Faculty who responded to questions concerning the most difficult aspects of webcasting $(n=135)$ ranked technical issues, $43(32 \%)$ and learning the software, $34(25 \%)$ as the two greatest challenges. However, many faculty, $47(35 \%)$ indicated that there were no difficulties.

Distribution of the recordings is, for the most part, contained behind firewalls. Course management systems are used as the repositories by 149 respondents (58\%). Other password protected sites such as iTunes private channel, and departmental websites and wikis are used by 31 respondents $(12 \%)$. Only 5 faculty $(2 \%)$ reported public distribution of their recordings on iTunes and YouTube public channels. Forty-eight respondents (19\%) indicated they did not know how the recordings were distributed.

Faculty who reported using webcasting technologies $(n=137)$ were asked if they believed that use of these technologies has improved student learning. Of the 86 responses obtained, 12 $(14 \%)$ believed learning was not improved, $10(12 \%)$ were unsure, and $64(74 \%)$ believed learning is improved by the use of these technologies. Faculty were then asked if students performed better on exams since the introduction of podcasts/lecture captures than in years prior to use of these technologies. Of the 34 respondents, 10 (29\%) indicated scores had improved, 5 $(15 \%)$ were unsure, and $19(56 \%)$ indicated that using the technologies did not improve their students' exam performance.

We performed correlation analyses to determine relationships between the use of podcasting or lecture capture technologies and the following 4 variables: school affiliation; faculty gender; total number of years teaching; or number of years teaching at this campus. Our

Journal of Teaching and Learning with Technology, Vol. 3, No. 1, June 2014. 
results indicate there was no correlation between any of these variables and the use of podcasting technologies.

Table 1

Relationship between Use of Podcast/Lecture Capture and Faculty Characteristics

\begin{tabular}{|c|c|c|c|c|c|c|c|c|}
\hline \multirow[b]{2}{*}{$\begin{array}{l}\text { Use } \\
\text { technologies }\end{array}$} & \multicolumn{2}{|c|}{$\begin{array}{l}\text { School Affiliation } \\
(\mathrm{n}=280)\end{array}$} & \multicolumn{2}{|c|}{ Gender $(n=260)$} & \multicolumn{2}{|c|}{$\begin{array}{l}\text { Yrs. Teaching } \\
(\mathrm{n}=252)\end{array}$} & \multicolumn{2}{|c|}{$\begin{array}{l}\text { Yrs. Teaching at this } \\
\text { campus } \\
(\mathrm{n}=119)\end{array}$} \\
\hline & $\begin{array}{l}\text { Dentistry } \\
\text { Medicine } \\
\text { Nursing }\end{array}$ & $\begin{array}{r}33 \\
108 \\
21\end{array}$ & $\begin{array}{l}\text { Female } \\
\text { Male }\end{array}$ & $\begin{array}{l}58 \\
87\end{array}$ & $\begin{array}{r}<1 \\
1-5 \\
6-10 \\
11-15 \\
16-20 \\
21-25 \\
26-30 \\
>30 \\
\end{array}$ & $\begin{array}{r}2 \\
20 \\
25 \\
22 \\
19 \\
18 \\
17 \\
17\end{array}$ & $\begin{array}{r}<1 \\
1-5 \\
6-10 \\
11-15 \\
16-20 \\
21-25 \\
26-30 \\
>30 \\
\end{array}$ & $\begin{array}{r}6 \\
28 \\
28 \\
15 \\
12 \\
10 \\
8 \\
6 \\
\end{array}$ \\
\hline $\begin{array}{l}\text { Don't use } \\
\text { technologies }\end{array}$ & $\begin{array}{l}\text { Dentistry } \\
\text { Medicine } \\
\text { Nursing }\end{array}$ & $\begin{array}{l}27 \\
73 \\
18\end{array}$ & $\begin{array}{l}\text { Female } \\
\text { Male }\end{array}$ & $\begin{array}{l}51 \\
64\end{array}$ & $\begin{array}{r}<1 \\
1-5 \\
6-10 \\
11-15 \\
16-20 \\
21-25 \\
26-30 \\
>30 \\
\end{array}$ & $\begin{array}{r}4 \\
19 \\
20 \\
13 \\
12 \\
14 \\
17 \\
11\end{array}$ & $\begin{array}{r}<1 \\
1-5 \\
6-10 \\
11-15 \\
16-20 \\
21-25 \\
26-30 \\
>30 \\
\end{array}$ & $\begin{array}{r}2 \\
38 \\
37 \\
21 \\
19 \\
10 \\
8 \\
6\end{array}$ \\
\hline Correlation* & $\begin{array}{l}\mathrm{V}=.050( \\
\mathrm{p}=.704\end{array}$ & & $\begin{array}{l}\mathrm{r}_{\Phi}=.04 \\
\mathrm{p}=.480\end{array}$ & & $\begin{array}{l}\mathrm{d}=-.021(2 \\
\mathrm{p}=.624)\end{array}$ & & $\mathrm{d}=.006(1$ & $\overline{566}$ \\
\hline
\end{tabular}

Tables 2 and 3 summarize basic themes that we identified from content analyses of participants' free-text responses to open-ended survey items regarding the advantages and disadvantages to faculty and students in the use of podcast and lecture capture software. Overwhelmingly $(n=80)$ faculty reported an advantage to students was the ability to use the recordings to review, as often as needed, difficult concepts for improved comprehension and exam preparation.

One limitation of this study is the response rate. Although the School of Dentistry and School of Nursing generated a $64 \%$ and $57 \%$ response rate, respectively, the School of Medicine response rate was only $24.5 \%$. This may be attributed to the email list provided by the School of Medicine which included all full-time faculty many of whom are exclusively involved in research and/or clinical teaching. We were unable to separate these individuals from faculty who engage in classroom instruction. Other factors may account for the low response rate. Asch et al (Asch 1997) reported a model predicting response rates which revealed that physicians have a $9.6 \%$ lower response rate on surveys than non-physicians, and anonymous surveys have a $9 \%$ lower response rate.

There are several methods recounted in the literature that attempt to assess and minimize response bias which can occur in even a high response rate survey (Fillion 1976; Lin and Schaeffer 1995; Hikmet 2003; Menachemi 2011; Asch 1997; Ford \& Bammer 2009). Two methods, comparing demographic characteristics of respondents to non-respondents, and contacting non-respondents following completion of the survey are not possible with anonymous 
Table 2A

Faculty Perceptions of the Benefits of Podcast/Lecture Capture for Students

\begin{tabular}{|l|l|}
\hline Themes identified & Sample Responses \\
\hline Advantage to students n=100 & \\
\hline Can review materials as often as needed (80) & $\begin{array}{l}\text { "Students can listen as often and when they like." } \\
\text { "Allows students to hear and see the content for review } \\
\text { or exam preparation purposes." } \\
\text { "Students can review the lecture for better } \\
\text { understanding." } \\
\text { "They can go back and review content they did not } \\
\text { understand the first time." } \\
\text { "Students have reported they like to go back and listen } \\
\text { to them again before exams." }\end{array}$ \\
\hline Allows asynchronous learning opportunities (20) & $\begin{array}{l}\text { "They manage their own time and repeat sessions when } \\
\text { needed." } \\
\text { "Allow the students take the lecture at whatever time } \\
\text { desired." } \\
\text { "View on their own time." }\end{array}$ \\
\hline
\end{tabular}

surveys such as this one. A third method, wave analysis (Hikmet \& Chen, 2003; Menachemi, Hikmet, et al, 2006; Montori et al, 2005), involves comparing survey answers of respondents who complete the survey in identifiable time units. These groups can be identified as early and late responders or fast, medium, and slow responders (Ford \& Bammer) based on whether they completed the survey following the initial call or following subsequent calls. We chose wave analysis to determine if responses to the questions, or demographic characteristics were significantly different among the three groups of respondents.

Following the initial email request, we received 245 responses, following the first reminder 107 responses, and following the second and final reminder 53 responses. We performed a Chi-square analysis comparing the characteristics of gender, school, and number of years teaching. We performed the same analysis on the attribute of use of the technology vs. nonuse of the technology which may have affected participation. We found no statistical significance in the responses between the three groups.

Despite the low response rate, we have demonstrated that the characteristics of the respondents are similar to the non-respondents, and the bias that might be present is unlikely to meaningfully impact our conclusions. 
Table 2B

Faculty Perceptions of the Benefits of Podcast/Lecture Capture for Faculty

\begin{tabular}{|l|l|}
\hline Themes identified & Sample Responses \\
\hline Advantage to faculty $\mathbf{n}=\mathbf{1 0 2}$ & $\begin{array}{l}\text { "Can record once and play for multiple classes." } \\
\text { "Good for snow days, in case class would be cancelled } \\
\text { you still have a way to cover material." } \\
\text { "Distribute to larger audiences with less time" } \\
\text { "Wider distribution of our materials." }\end{array}$ \\
\hline None (31) & $\begin{array}{l}\text { "Rather than spending time lecturing I can view } \\
\text { outcomes, edit, enhance \& adapt course material." } \\
\text { "Able to be consistent in the instruction across numerous } \\
\text { sessions." } \\
\text { "Helps me refine what is important." } \\
\text { "Review and make improvements on delivery." }\end{array}$ \\
\hline Helpful to the students (15) & $\begin{array}{l}\text { "It gives the students another way of revisiting the } \\
\text { lecture." } \\
\text { "[students] have RAVED about these Podcasts as adding } \\
\text { richness." } \\
\text { "They appreciate that we are trying to integrate } \\
\text { technology for them into the presentation." }\end{array}$ \\
\hline
\end{tabular}

\section{Table $3 \mathrm{~A}$}

Faculty Perceptions of the Disadvantages of Podcast/Lecture Capture for Students

\begin{tabular}{|c|c|}
\hline Themes identified & Sample Responses \\
\hline \multicolumn{2}{|l|}{ Disadvantages to students $n=97$} \\
\hline \multicolumn{2}{|l|}{ None/don’t know (29) } \\
\hline Inability to interact with instructor (23) & $\begin{array}{l}\text { "Loss of learner teacher interactions." } \\
\text { • "No interaction with lecturer." } \\
\text { - "They can't ask a question to clarify as they } \\
\text { could during a live lecture." } \\
\text { - "I would assume it is less interactive for them." }\end{array}$ \\
\hline Less likely to attend class (18) & $\begin{array}{l}\text { "They will have incentive to skip live lectures." } \\
\text { "It provides an outlet/excuse for students not to attend } \\
\text { lecture." } \\
\text { "Reliance on the podcasts and thinking they do not need } \\
\text { to attend class." }\end{array}$ \\
\hline Technology issues (17) & $\begin{array}{l}\text { "Some students in rural areas have difficulty accessing } \\
\text { them due to tech issues." } \\
\text { "Very large file size." } \\
\text { "Accessing another system to view the lectures." } \\
\text { "Some students do not have a computer at home." }\end{array}$ \\
\hline Missing material delivered that is not recorded (5) & $\begin{array}{l}\text { "Miss questions asked in class; content before or after } \\
\text { the recording is being made." } \\
\text { They miss any visual material not on the screen and } \\
\text { student questions." }\end{array}$ \\
\hline Lack of student engagement (5) & $\begin{array}{l}\text { "They can pay less attention in class." } \\
\text { "May not pay attention in lecture as they have a fall- } \\
\text { back option." } \\
\text { "May not be as engaged if watching lecture remotely." }\end{array}$ \\
\hline
\end{tabular}

Journal of Teaching and Learning with Technology, Vol. 3, No. 1, June 2014. 
Table 3B

Faculty Perceptions of the Disadvantages of Podcast/Lecture Capture for Faculty

\begin{tabular}{|l|l|}
\hline Themes identified & Sample Responses \\
\hline Disadvantages to faculty $\mathbf{n}=\mathbf{8 7}$ & \\
\hline None (28) & $\begin{array}{l}\text { "getting access to the equipment." } \\
\text { "When equipment did not work, this was a nightmare." } \\
\text { "Cumbersome recording" } \\
\text { "time consuming to get software up and running." }\end{array}$ \\
\hline Lechnology issues (28) & $\begin{array}{l}\text { "may reduce class attendance" } \\
\text { "students don't come to class" } \\
\text { "Students don't feel obligated to attend and are unable to } \\
\text { participate in discussion" }\end{array}$ \\
\hline Little faculty-student interaction (9) & $\begin{array}{l}\text { "No audience interaction." } \\
\text { "I like to give lectures that are interactive and can't do } \\
\text { that with a recording." } \\
\text { "lack of interaction with learners - can't gauge if there } \\
\text { are problems with the message." } \\
\text { "Discourages the use of discussion in class." }\end{array}$ \\
\hline Time-consuming to produce (8) & $\begin{array}{l}\text { "Finding time to record them if not done live." } \\
\text { "Pre-recorded podcasts can take a lot of time to } \\
\text { produce." } \\
\text { "Time to do it and learn the software/ hardware." }\end{array}$ \\
\hline
\end{tabular}

\section{Discussion}

The purpose of this study was to assess faculty use of podcasts and lecture capture technologies in this campus's health sciences education programs. Much has been written about these instructional technologies from the student's point of view. We wanted to hear from faculty about their experiences with this relatively new method of delivering instruction and their perceptions of the advantages and disadvantages of doing so. Specifically, our research questions were intended to determine the following: 1) the extent to which health sciences faculty are using these technologies, 2) differences in use and perceptions of webcasting technologies among faculty based on health science program, faculty gender, or years of teaching experience, 3) faculty perceptions of the advantages / disadvantages for themselves and for their students, and 4) perceived barriers to using the technologies.

Regarding the extent to which faculty use webcasting technologies, although lecture capture and podcasting software systems are in use at each of the health sciences schools represented by the survey, only about one-third of the faculty respondents reported using them. Furthermore, one in five faculty reported that they did not know these systems were available and $30 \%$ do not use them as teaching tools. We found that of the $34 \%$ who do use these technologies, the majority are using lecture capture methods rather than pre-recording materials for their students. Additionally, although many of these faculty did not know the name of the available software product or system, this did not deter them from producing the recordings.

Our study failed to reveal any correlations between faculty gender and the use of podcast or lecture capture technologies. Much research has been conducted on the issue of gender and technology. Studies have been conducted on gender differences in perception of technology 
(Brunner \& Bennett, 1998), confidence in using technology (Hon Keung \& Alison Lai Fong, 2012), acceptance of (Padilla-Meléndez, del Aguila-Obra, \& Garrido-Moreno, 2013), and attitude toward technology (Bain \& Rice, 2006). Many of these studies focus on students in K12 , though some recent work has been done on students in teacher education programs (Naaz, 2012; Su Luan \& Hanafi, 2007). While these studies show there are some gender difference in approaches to technology, there was nothing conclusive found in the literature about faculty gender differences in relation to their use of technology in the classroom.

Table 4

Comparison of three waves of respondents on attributes that may have influenced participation

\begin{tabular}{|l|r|r|r|r|}
\hline \multicolumn{5}{|c|}{ Respondents } \\
\hline & $\begin{array}{c}\text { Fast } \\
N=245\end{array}$ & $\begin{array}{c}\text { Medium } \\
N=107\end{array}$ & \multicolumn{1}{c|}{$\begin{array}{l}\text { Slow } \\
N=53\end{array}$} \\
\hline Gender & & & & \\
\hline Male & $123(61.5 \%)$ & $51(58.6 \%)$ & $32(62.7 \%)$ & \\
\hline Female & $77(38.5 \%)$ & $36(41.4 \%)$ & $19(37.2 \%)$ & .881 \\
\hline Total & $200(100 \%)$ & $87(100 \%)$ & $51(100 \%)$ & \\
\hline School & & & & \\
\hline Dentistry & $38(15.7 \%)$ & $21(20.6 \%)$ & $9(17.0 \%)$ & \\
\hline Medicine & $170(70.2 \%)$ & $65(63.7 \%)$ & $39(73.6 \%)$ & \\
\hline Nursing & $34(14 \%)$ & $16(15.7 \%)$ & $5(9.4 \%)$ & \\
\hline Total & $242(100 \%)$ & $102(100 \%)$ & $53(100 \%)$ & \\
\hline Year teaching & & & & \\
\hline Don't teach/Didn't answer & $50(20.4 \%)$ & $22(20.6 \%)$ & $2(3.8 \%)$ & \\
\hline$<1$ & $1(0.4 \%)$ & $4(3.7 \%)$ & $1(1.9 \%)$ & \\
\hline $1-5$ & $35(14.3 \%)$ & $19(17.8 \%)$ & $11(20.8 \%)$ & \\
\hline $6-10$ & $33(13.5 \%)$ & $11(10.3 \%)$ & $11(20.8 \%)$ & \\
\hline $11-15$ & $27(11.0 \%)$ & $18(16.8 \%)$ & $5(9.4 \%)$ & \\
\hline $16-20$ & $26(10.6 \%)$ & $6(5.6 \%)$ & $8(15.1 \%)$ & \\
\hline $21-25$ & $28(11.4 \%)$ & $10(9.3 \%)$ & $7(13.2 \%)$ & \\
\hline $26-30$ & $29(11.8 \%)$ & $8(7.5 \%)$ & $4(7.5 \%)$ & \\
\hline$>30$ & $16(6.5 \%)$ & $9(8.4 \%)$ & $4(7.5 \%)$ & \\
\hline Total & $245(100 \%)$ & $(100 \%)$ & $(100 \%)$ & \\
\hline Technology & & & & \\
\hline Use & $96(57.1 \%)$ & $48(64.9 \%)$ & $18(46.1 \%)$ & \\
\hline Don't use & $72(42.9 \%)$ & $26(35.1 \%)$ & $21(53.8 \%)$ & \\
\hline Total & $168(100 \%)$ & $74(100 \%)$ & $39(100 \%)$ & \\
\hline
\end{tabular}

We likewise were unable to find any correlations between use of these technologies and health science school, total years of teaching, or years of teaching at this campus. We found that faculty who have been teaching for only a few years are no more likely to use the technologies than faculty who have teaching for 20 years or more. We hypothesized that faculty with a long history at this campus would be more likely to use these technologies due to the tradition and culture on this urban campus which was an early-adopter of learning technologies and strongly promotes and supports its use in the classroom. However, our findings did not support this hypothesis.

Overall, faculty perceived the webcasting technologies to be advantageous. The number of comments regarding advantages to students and faculty (171) outnumbered the comments on the disadvantages (127). One advantage listed numerous times is that recordings can be viewed 
by students anytime; this may also be a disadvantage in that if the recordings can be viewed anytime, students may not attend class. Other investigators (Bhatti et al., 2009; Long \& Edwards, 2010) have also cited as advantages the convenience and flexibility of podcasts as well as their ability to be widely disseminated. Schreiber (Schreiber et al., 2010) noted that for students with certain learning styles, or slow learners, the ability for students to repeatedly review the material is a huge benefit. Some of the shortcomings of podcasts/lecture capture were also identified by other authors and include a lack of student engagement (Long \& Edwards, 2010; Schreiber et al., 2010) and decreased motivation to attend class (Schreiber et al., 2010). In the current study, technical issues were identified as problems for both faculty and students. Similarly, Bhatti noted that students may have difficulty with online accessibility (Bhatti et al., 2009). Previous studies have identified other drawbacks such as technical issues with hardware /software systems and production time (Bhatti et al., 2009; Jham et al., 2008).

The current study found that a perceived lack of time and training were the principal barriers to faculty adoption of the webcasting technologies. Though the wide variety of software available was not presented as a problem by respondents, such an array of choices may contribute to faculty perceptions that there is too much to learn to make this a viable method for instruction delivery. There is currently no initiative at the campus level to standardize the software, hardware or distribution mechanism for the recordings. Such standardization may encourage more use by faculty, especially those reporting lack of time and training as barriers to implementation.

An important aspect to incorporating podcasting technologies is the effect on teaching and learning outcomes. Interestingly, in this study we found that more faculty than not believe use of these technologies enhances learning. However, relatively few faculty had evidence of improved test scores as a result of incorporating these instructional methods. This may indicate that faculty are not routinely measuring the impact of these technologies on student learning. Their perceptions of enhanced learning may also be derived from subjective measures, such as student evaluations and comments. From a pedagogical viewpoint, multimedia learning theory suggests that podcasting technologies might enhance learning by allowing students to process both auditory and visual information together, and by enabling them to pause and replay podcasted material, thereby using repetition to activate memory circuits (Mayer, 2001). However, a randomized controlled trial of learning outcomes in medical education found no significant difference in test performance between students receiving live lectures and podcasted lectures, although students found the live lecture format more engaging (Schreiber et al., 2010). Other studies have shown equal or better performance among students using these technologies compared to lecture alone (Bhatti et al., 2009; Vogt et al., 2010; Zanussi et al., 2011).

It has been argued that because podcasts are usually engaged by students in a passive and solitary manner, podcasts may actually hinder learning. However, faculty can structure podcasts so as to encourage more active learning by incorporating questions, interactive games, assignments, or student group activities associated with the content objectives. In addition, the style, length and delivery of podcasted content may affect student engagement and learning (Long \& Edwards, 2010). Alternatively, if pre-recorded podcasts are utilized, class time which was previously used for lecture may be restructured for more interactive learning activities. A recent survey of webcasting technologies in dental education found that as a result of using these technologies, faculty alter the way they teach (Horvath et al., 2013). Therefore, it is critical that faculty development efforts keep pace with these instructional technologies so that faculty can learn techniques to enhance the effectiveness and utility of such teaching tools. Horvath et al.

Journal of Teaching and Learning with Technology, Vol. 3, No. 1, June 2014. 
concluded that webcasting technologies may serve as a useful adjunct to the classroom environment. To maximize the effectiveness of these technologies, the authors offered several "best practices" which included the following: having sufficient preparation time and instructional objectives for faculty, complying with copyright / intellectual property laws, providing IT support, combining recordings with other classroom activities, utilizing shorter content segments rather than full-length lecture recordings, and soliciting student evaluations regarding these technologies (Horvath et al., 2013).

The current study was limited to full-time faculty. Although many part-time faculty teach in health sciences programs, we have found from previous attempts at surveying this group that they tend to be less responsive and more difficult to contact via email than their full-time colleagues. Additionally, this survey did not distinguish between tenured/tenure track and nontenured/non tenure track faculty; this factor may have an impact on teaching load, support level, and availability of instructional technology resources.

Despite these limitations, we believe our study findings fill a void in the literature regarding the use and perceptions of podcasting technologies by health science faculty. Ultimately, the goal of any instructional method should be to enhance learning and future research will explore teaching and learning outcomes as a result of the use of these technologies.

\section{Conclusion}

We found a wide array of technologies to record lectures and present additional course materials electronically in use across all 3 health sciences schools. Of the $30 \%$ of faculty who reported that they are not currently webcasting, most indicated that they plan to do so in the next 2 years. Faculty identified more advantages than disadvantages for themselves and their students in using these technologies. The software and hardware will undoubtedly continue to change and develop but these methods of delivering instructional content have gained acceptance in health sciences education at this campus.

Further research is needed regarding the role that faculty status (i.e., full/part-time, tenure/tenure-track) plays in faculty use of technology in the classroom as well as faculty motivation and institutional support for using such technology. Future studies should attempt to identify whether the investment in and use of such instructional technologies varies by discipline e.g., medical schools versus engineering or law schools, or by type and size of institution, as well as the impact that these technologies have upon student learning outcomes.

\section{Acknowledgements}

The authors wish to thank David Zahl and Steve Graunke for their assistance with statistical calculations and the faculty at the Schools of Dentistry, Medicine, and Nursing for their time in completing the survey.

\section{Ethical approval}

The Institutional Review Board at Indiana University, Bloomington, Indiana reviewed and approved the protocol, IRB \# EX1008-31B. 


\section{References}

Bain, C. D., \& Rice, M. L. (2006). The Influence of Gender on Attitudes, Perceptions, and Uses of Technology. [Article]. Journal of Research on Technology in Education, 39(2), 119-132. doi: 10.1080/15391523.2006.10782476

Bhatti, I., Jones, K., Richardson, L., Foreman, D., Lund, J., \& Tierney, G. (2011). E learning versus lecture: Which is the best approach to surgical teaching? Colorectal Diseases, 13(4), 45962. doi: $10.1111 / \mathrm{j} .1463-1318.2009 .02173 . \mathrm{x}$

Bollmeier, S. G., Wenger, P. J., \& Forinash, A. B. (2010). Impact of online lecture-capture on student outcomes in a therapeutics course. American Journal of Pharmaceutical Education, 74(7), 127. doi: 10.5688/aj7407127

Brunner, C., \& Bennett, D. (1998). Technology perceptions by gender. [Article]. Education Digest, 63(6), 56.

Cain, J., \& Fox, B. I. (2009). Web 2.0 and pharmacy education. American Journal of Pharmaceutical Education, 73(7), 120. doi: 10.5688/aj7307120

Copley, J. (2007). Audio and video podcasts of lectures for campus-based students: production and evaluation of student use. [Article]. Innovations in Education \& Teaching International, 44(4), 387-399. doi: 10.1080/14703290701602805

Corl, F. M., Johnson, P. T., Rowell, M. R., \& Fishman, E. K. (2008). Internet-based dissemination of educational video presentations: a primer in video podcasting. AJR. American Journal of Roentgenology, 191(1), W23-27. doi: 10.2214/AJR.07.2637

Elkind, M. S. (2009). Teaching the next generation of neurologists. Neurology, 72(7), 657-663. doi: 10.1212/01.wnl.0000342516.08077.55

Forbes, M. O., \& Hickey, M. T. (2008). Podcasting: implementation and evaluation in an undergraduate nursing program. Nurse Educator, 33(5), 224-227. doi:

10.1097/01.NNE.0000334775.98018.e8

Greenfield, S. (2011). Podcasting: a new tool for student retention? Journal of Nursing Education, 50(2), 112-114. doi: 10.3928/01484834-20101230-06

Hadley, J., Kulier, R., Zamora, J., Coppus, S. F., Weinbrenner, S., Meyerrose, B., . . Khan, K. S. (2010). Effectiveness of an e-learning course in evidence-based medicine for foundation (internship) training. Journal of the Royal Society of Medicine, 103(7), 288-294. doi:

$10.1258 / \mathrm{jrsm} .2010 .100036$

Hon Keung, Y., \& Alison Lai Fong, C. (2012). Gender Difference of Confidence in Using Technology for Learning. [Article]. Journal of Technology Studies, 38(2), 74-79. 
Hopp, L. (2010). Designing podcasts for clinical nurse specialist education. Clinical Nurse Specialist, 24(2), 106-109. doi: 10.1097/NUR.0b013e3181d33d80

Horvath, Z., O'Donnell, J. A., Johnson, L. A., Karimbux, N. Y., Shuler, C. F., \& Spallek, H. (2013). Use of lecture recordings in dental education: assessment of status quo and recommendations. Journal of Dental Education, 77(11), 1431-1442.

Jham, B. C., Duraes, G. V., Strassler, H. E., \& Sensi, L. G. (2008). Joining the podcast revolution. Journal of Dental Education, 72(3), 278-281. doi: 72/3/278 [pii]

Johnson, L., \& Grayden, S. (2006). Podcasts--an emerging form of digital publishing. International Journal of Computerized Dentistry, 9(3), 205-218.

Kardong-Edgren, S., \& Emerson, R. (2010). Student adoption and perception of lecture podcasts in undergraduate bachelor of science in nursing courses. Journal of Nursing Education, 49(7), 398-401. doi: 10.3928/01484834-20100224-04

Kennedy, G., Gray, K., \& Tse, J. (2008). 'Net Generation' medical students: technological experiences of pre-clinical and clinical students. Medical Teacher, 30(1), 10-16. doi: $10.1080 / 01421590701798737$

Long, S. R., \& Edwards, P. B. (2010). Podcasting: making waves in millennial education. Journal for Nurses in Staff Development, 26(3), 96-101; quiz 102-103. doi: 10.1097/NND.0b013e3181993a6f

Lymn, J., \& Bowskill, D. (2010). Learning on the move. Nursing Standard, 24(31), 61.

Mayer, R. E. (2001). Multimedia learning. New York: Cambridge University Press. doi: 10.1017/CBO9781139164603

McCartney, P. R. (2006). Podcasting in nursing. MCN; American Journal of Maternal Child Nursing, 31(4), 270. doi: 10.1097/00005721-200607000-00014

McKinney, A. A., \& Page, K. (2009). Podcasts and videostreaming: Useful tools to facilitate learning of pathophysiology in undergraduate nurse education? Nurse Education in Practice, 9(6), 372-376. doi: 10.1016/j.nepr.2008.11.003

Meade, O., Bowskill, D., \& Lymn, J. S. (2009). Pharmacology as a foreign language: a preliminary evaluation of podcasting as a supplementary learning tool for non-medical prescribing students. BMC Medical Education, 9, 74. doi: 10.1186/14726920-9-74

Naaz, S. T. (2012). Attitude of Prospective Teachers Towards Computer Technology: A Study. [Article]. Golden Research Thoughts, 1(9), 1-3. 
Nagler, A., Andolsek, K., Dossary, K., Schlueter, J., \& Schulman, K. (2010). Addressing the systems-based practice requirement with health policy content and educational technology. Medical Teacher, 32(12), e559-565. doi: 10.3109/0142159X.2010.528809

Nast, A., Schafer-Hesterberg, G., Zielke, H., Sterry, W., \& Rzany, B. (2009). Online lectures for students in dermatology: a replacement for traditional teaching or a valuable addition? Journal of the European Academy of Dermatology and Venereology, 23(9), 1039-1043. doi:

$10.1111 / \mathrm{j} .1468-3083.2009 .03246 . \mathrm{x}$

O'Neill, E., Power, A., Stevens, N., \& Humphreys, H. (2010). Effectiveness of podcasts as an adjunct learning strategy in teaching clinical microbiology among medical students. Journal of Hospital Infection, 75(1), 83-84. doi: 10.1016/j.jhin.2009.11.006

Owston, R., Lupshenyuk, D., \& Wideman, H. (2011). Lecture capture in large undergraduate classes: Student perceptions and academic performance. Internet and Higher Education, 14(4), 262-268. doi: 10.1016/j.iheduc.2011.05.006

Padilla-Meléndez, A., del Aguila-Obra, A. R., \& Garrido-Moreno, A. (2013). Perceived playfulness, gender differences and technology acceptance model in a blended learning scenario. [Article]. Computers \& Education, 63, 306-317. doi: 10.1016/j.compedu.2012.12.014

Patasi, B., Boozary, A., Hincke, M., \& Jalali, A. (2009). The utility of podcasts in Web 2.0 human anatomy. Medical Education, 43(11), 1116. doi: 10.1111/j.1365-

2923.2009.03471.x

Pilarski, P. P., Alan Johnstone, D., Pettepher, C. C., \& Osheroff, N. (2008). From music to macromolecules: using rich media/podcast lecture recordings to enhance the preclinical educational experience. Medical Teacher, 30(6), 630-632. doi:

$10.1080 / 01421590802144302$

Rainsbury, J. W., \& McDonnell, S. M. (2006). Podcasts: an educational revolution in the making? Journal of the Royal Society of Medicine, 99(9), 481-482. doi: 10.1258/jrsm.99.9.481

Read, B. (2007). How to Podcast Campus Lectures. Chronicle of Higher Education, 53(21), A32.

Reynolds, P. A., Mason, R., \& Eaton, K. A. (2008). Webcasting: casting the web more widely. British Dental Journal, 204(3), 145-149. doi: 10.1038/bdj.2008.55

Rowell, M. R., Corl, F. M., Johnson, P. T., \& Fishman, E. K. (2006). Internet-based dissemination of educational audiocasts: a primer in podcasting--how to do it. AJR. American Journal of Roentgenology, 186(6), 1792-1796. doi: 10.2214/AJR.05.1315

Ruiz, J. G., Mintzer, M. J., \& Leipzig, R. M. (2006). The impact of e-learning in medical education. Acad Med, 81(3), 207-212. 
Schlairet, M. C. (2010). Efficacy of Podcasting: Use in Undergraduate and Graduate Programs in a College of Nursing. Journal of Nursing Education, 1-5. doi: 10.3928/01484834-20100524-08

Schreiber, B. E., Fukuta, J., \& Gordon, F. (2010). Live lecture versus video podcast in undergraduate medical education: A randomised controlled trial. BMC Medical Education, 10, 68. doi: 10.1186/1472-6920-10-68

Shantikumar, S. (2009). From lecture theatre to portable media: students' perceptions of an enhanced podcast for revision. Medical Teacher, 31(6), 535-538.

doi:10.1080/01421590802365584

Stiffler, D., Stoten, S., \& Cullen, D. (2010). Podcasting as an Instructional Supplement to Online Learning: A Pilot Study. Computers, Informatics, Nursing : CIN. doi:10.1097/NCN.0b013e3181fc3fdf

Straub, E. T. (2009). Understanding Technology Adoption: Theory and Future Directions for Informal Learning. Review of Educational Research, 79(2), 625-649.

doi: $10.3102 / 0034654308325896$

Su Luan, W., \& Hanafi, A. (2007). Gender Differences in Attitudes towards Information Technology among Malaysian Student Teachers: A Case Study at Universiti Putra Malaysia. [Article]. Journal of Educational Technology \& Society, 10(2), 158-169.

Vogt, M., Schaffner, B., Ribar, A., \& Chavez, R. (2010). The impact of podcasting on the learning and satisfaction of undergraduate nursing students. Nurse Education in Practice, 10(1), 38-42. doi: 10.1016/j.nepr.2009.03.006

Walmsley, A. D., Lambe, C. S., Perryer, D. G., \& Hill, K. B. (2009). Podcasts--an adjunct to the teaching of dentistry. British Dental Journal, 206(3), 157-160. doi: 10.1038/sj.bdj.2009.58

Zanussi, L., Paget, M., Tworek, J., \& McLaughlin, K. (2011). Podcasting in medical education: can we turn this toy into an effective learning tool? Advances in Health Sciences Education: Theory and Practice. doi: 10.1007/s10459-011-9300-9 
Appendix A. Software packages identified by faculty respondents

Software Name \# of users

Accordant 3

Adobe Captive 8

Adobe Connect $\quad 62$

Adobe Presenter 31

Apple Podcast Producer 3

Camtasia 2

Echo 360

Elluminate 1

iShowU, Quicktime Pro 1

Lecturnity 1

Mediasite 13

Perfect Meeting 1

ProfCast 14

Snapkast $\quad 10$

Wirecast 2 